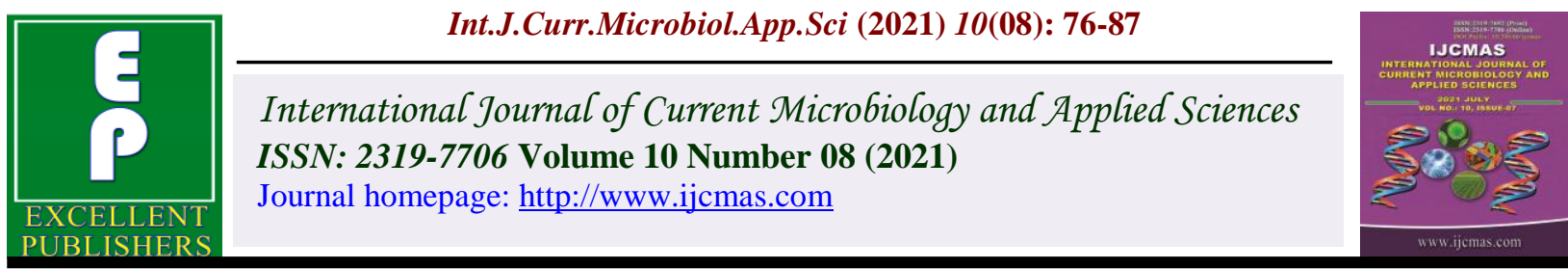

\title{
Effect of the Aqueous Extract of the Trunk Bark of Commiphora pedunculata (Burseraceae) on Type 1 Diabetes induced by the Streptozotocin in Rats
}

\author{
Lawa Wanlibélé ${ }^{1 *}$, Ntchapda Fidèle ${ }^{1}$, Kemeta Azambou David Romain ${ }^{1}$, \\ Talla Ernest Rodrigue ${ }^{1}$, Miaffo David ${ }^{2}$, Sanone Guersom ${ }^{1}$ and Sokeng Dongmo Selestin ${ }^{1}$ \\ ${ }^{1}$ Department of Biological Sciences, Faculty of Science, University of Ngaoundéré, \\ Cameroon, P.O. Box 454, Ngaoundéré, Cameroon \\ ${ }^{2}$ Department of Life and Earth Sciences, Higher Teachers' Training College, University of \\ Maroua, Cameroon, P.O. Box 55, Maroua, Cameroon \\ *Corresponding author
}

\section{Keywords \\ Commiphora pedunculata, hyperglycemia, Diabetes, Streptozotocin \\ Article Info \\ Accepted: \\ 10 July 2021 \\ Available Online: \\ 10 August 2021}

Diabetes mellitus is a metabolic disease characterized by hyperglycemia resulting from the lack insulin secretion, insulin action, or both of these associated abnormalities. The objective of this study was to evaluate the anti-hyperglycemic properties of aqueous extract of Commiphora pedunculata on type 1 diabetes in rats induced with streptozotocin. Type 1 diabetes was induced in normal rats by intra-peritoneal injection of streptozotocin. Seventy-two hours later, the blood glucose level of the animals was measured and the animals with a blood glucose level greater than $1.26 \mathrm{~g} / \mathrm{L}$ were selected to continue the experiment. After induction of diabetes, diabetic rats will be treated for 28 days with glibenclamide and $C$. pedunculata extract at different doses $(75 ; 150$ and 300mg / kg). Throughout the experiment, the blood sugar level, body weight, food and water consumption of the rats were evaluated. At the end of the experiment, the animals were sacrificed and the blood collected for the glucose assay, insulin, and biochemical parameters. The pancreas of the animals was removed for histological sections. The results obtained clearly show that streptozotocin induced in animals, diabetes characterized by hyperglycemia and deregulation of biological factors (polyphagia, polyuria, polydipsia, weight loss). However, oral administration of the aqueous extract at daily doses of 150 and $300 \mathrm{mg} / \mathrm{kg}$ caused a decrease in serum glucose concentration $(62.5$ and $57 \mathrm{mg} / \mathrm{kg})$, total cholesterol (11.34 and 15\%), triglycerides (7.3 and 4.20\%) respectively. On the other hand, the administration of the aqueous extract of $\mathrm{C}$. pedunculata made it possible to improve the physiological parameters in these rats, by reducing polyphagia, polydipsia and polyuria, and by protecting these rats against excessive loss of body weight in treated diabetic rats compared to untreated diabetics. Histology of the pancreas showed a decrease in the size of the islets of Langerhans in untreated diabetic rats compared to normal rats. On the other hand, in rats treated with glibenclamide and with the aqueous extract at different doses, we obtained an increase in the size of the islets of Langerhans compared to the untreated rats. The present study shows that the aqueous extract of $C$. pedunculata has an anti-diabetic effect on type 1 diabetes, hence its use by herbalists in the treatment of this pathology. 


\section{Introduction}

Diabetes is a generic term for a group of metabolic disorders characterized by chronic hyperglycemia. Pathology, characterized by permanent hyperglycemia resulting from a deficit in insulin secretion or the inability of the body to use the insulin it secretes effectively. There are two specific types of diabetes; type I diabetes (or insulin-dependent diabetes) which is as a result of the consequence of a selective autoimmune destruction of insulin-secreting $\beta$ cells (1). Type II diabetes (or non-insulin-dependent diabetes) which results from inadequate use of insulin by the body (2).

Type 1 diabetes is a carbohydrate metabolism disorder that increasingly affects people around the world and has today become a real public health problem. It affects around 366 million people, on all continents, or around $4 \%$ of the world's population (3). According to the IDF since the first edition in 2000 , the estimated prevalence of diabetes in people aged 20 to 79 has increased from 151 million (4.6\% of the world population at the time) to 463 million $(9,3 \%)$ today and this number is expected to reach 578 million in 2030 and 700 million in 2045 (4). In Africa, 19 million people currently have diabetes and this number could reach 47 million by 2045 (4). In Cameroon, about $5.2 \%$ (with a $4.4-6.4 \%$ margin of uncertainty) of people have diabetes (4). In rural Cameroon's areas, 2 to $3 \%$ of people are believed to be living with diabetes, while this figure fluctuates between 6 and $8 \%$ in urban areas.

The therapeutic management of diabetes currently relies strictly on diets, administration of insulin and oral antidiabetic drugs such as sulfamides, hypoglycaemic, biguanides and inhibitors of digestive carbohydrate enzymes. The high cost of antidiabetic drugs, their harmful side effects (insulin resistance, hypoglycemia, coma, gastrointestinal disorders, etc.) are some of the reasons why most diabetic patients abandon conventional drugs in favor of herbal medicine.

Therefore, in this study, we undertook to evaluate the anti-diabetic effects of Commiphora pedunculata which is a shrub of the Burseraceae family, traditionally used in Africa as an anti-parasitic inflammatory and anti-sickle cell anaemia (2). However, no scientific work has been done on the antidiabetic properties on the type I diabetes model induced by streptozotocin on this plant.

\section{Materials and Methods}

\section{Plant material}

Commiphora pedunculata (Burseraceae) was collected in November 2017, in mayo-kani division, far north region. The identification was made at the national herbarium of Cameroon in Yaoundé by comparison with the sample collected and deposited with reference number: $36346 / \mathrm{HNC}$ collected by C. Geerling in 1974.

\section{Animal material}

Male rats (30) of body weight between 110 and $200 \mathrm{~g}$ were used to induce type 1 diabetes. These animals were reared in the animal facility of the University of Ngaoundéré at room temperature. They were exposed to about 12 hours of darkness (night) and 12 hours of light (day) daily, and were given unlimited quantity of food and water.

\section{Preparation of the aqueous extract}

The fresh bark of Commiphora pedunculata was harvested, washed, dried and then crushed. Thus, $1500 \mathrm{~g}$ of bark powder was soaked in 4 liters of distilled water for 24 hours. After heating at a temperature of 90- 
$100^{\circ} \mathrm{C}$ for $20-30$ minutes, the obtained broth was kept at the boil. After decantation, the concoction was filtered using No3 whattman paper. Then, evaporation in an autoclave at $40^{\circ} \mathrm{C}$ of $2.5 \mathrm{~L}$ was carried through and we obtained $43.5 \mathrm{~g}$ (ie a yield of $2.9 \%$ ).

\section{Phytochemical study}

In order to determine the different families of chemical compounds responsible for the diuretic activity that are present in the bark of the trunk of $C$. pedunculata, a phytochemical study was carried out. The analytical test for the identification of the different groups of metabolites in the raw extract of the leaves was carried out at the Institute of Medicinal Plants for Medicinal Research of Cameroon. Therefore, the method described by Chen et al., in 2011 was used. In the study of the identification of the different structures of chemical compounds responsible for the diuretic activity, a preliminary test of the phytochemical study was carried out. Briefly, the essential oil of the aqueous extract of $C$. pedunculata was extracted with hexane.

\section{D- glucose tolerance test}

Twenty (25) male rats aged 10 to 12 weeks were fasted for 16 hours then divided into 5 groups of 5 rats each and treated as follows: group 1 (control group) received distilled water at a volume of $10 \mathrm{ml} / \mathrm{kg}$ of body weight; group 2 (reference group) received glibenclamide at a dose of $0.3 \mathrm{mg} / \mathrm{kg}$ of body weight; Groups 3, 4 and 5 received the extract at doses of $75 \mathrm{mg} / \mathrm{kg}, 150 \mathrm{mg} / \mathrm{kg}$ and $300 \mathrm{mg}$ / kg body weight respectively.

Immediately after partitioning, the initial blood glucose levels were taken at time t0. Immediately, the animals were force-fed with distilled water, glibenclamide and the different doses of extract according to the groups mentioned above. Ninety minutes (90min) later, $3 \mathrm{~g} / \mathrm{kg}$ of D-glucose were force-fed to the animals. Then the blood sugar was evaluated every 30 minutes for 2 hours using an Accu check glucometer and strips.

\section{Induction and treatment of diabetes}

Type I diabetes has been induced using streptozotocin. In fact, intra-peritoneal injection of streptozotocin at a single dose of $60 \mathrm{mg} / \mathrm{kg}$ was carried out in normal rats on an empty stomach for 24 hours.

One hour later, glucose $(3 \mathrm{~g} / \mathrm{kg})$ was administered orally to each animal in order to avoid possible hypoglycaemic shock. Seventytwo hours after the injection of streptozotocin, a blood glucose assessment was performed and rats with blood glucose greater than 150 $\mathrm{mg} / \mathrm{dL}$ were considered diabetic.

After induction of diabetes, the animals were treated for 21 days as follows:

Group 1 (normal control) normal rats are fed distilled water $(10 \mathrm{ml} / \mathrm{kg})$ by gavage;

Group 2 (diabetic control) diabetic rats received distilled water $(10 \mathrm{ml} / \mathrm{kg})$ orally;

Group 3 (positive control) diabetic rats received glibenclamide at a dose of $3 \mathrm{mg} / \mathrm{kg}$ orally;

Groups 4, 5 and 6 (test controls) the diabetic rats received the aqueous extract by gavage at the respective doses of $75 \mathrm{mg} / \mathrm{kg}, 150 \mathrm{mg} /$ $\mathrm{kg}$ and $300 \mathrm{mg} / \mathrm{kg}$.

Throughout the experiment, the blood glucose, body weight, food and water consumption of the animals were measured daily. At the end of the experiment, the animals were sacrificed then the blood of the animals was collected for biochemical assays and the organs were collected for histological sections. 


\section{Statistical analyzes}

The results were expressed as the mean \pm Mean Standard Error (ESM). GraphPad Prism 5.0 software was used for analysis of variance (ANOVA) followed by the Turkey test. The differences were significant at the 5\% probability level $(\mathrm{P}<0.05)$.

\section{Results and Discussion}

\section{Qualitative phytochemical analysis}

Table I below shows the different families of chemical compounds present in the aqueous extract of $C$. pedunculata. We notice in this table that this plant is rich in compounds such as phenol compounds, flavonoids, tannins, saponins, alkaloids, anthraquinones and terpenoids. On the other hand, glucosides, coumarin and lipids are absent.

Effect of aqueous extract of Commiphora pedunculata on the D-glucose tolerance test

Figure 1 below shows the effect of $C$. pedunculata aqueous extract on the D-glucose tolerance test. We notice in this figure that the blood sugar of the rats increases significantly $(\mathrm{P}<0.05)$ in all the groups at $30 \mathrm{~min}$ after administration of D-glucose. This glycaemia decreased in a non-significant way in the animals of the control group at time intervals of 60, 90 and 120 min compared to the 30th min. The aqueous extract, like glibenclamide, caused a very significant decrease $(\mathrm{P}<0.01)$ in blood sugar level at all-time interval compared to the 30th min.

Effect of aqueous extract of Commiphora pedunculata on the body weight of animals

Figure 2 below shows the effect of the aqueous extract of $C$. pedunculata on the change in body weight of the animals throughout the experiment. We note in this figure a highly significant decrease $(\mathrm{p}<0.001)$ in body weight in diabetic animals treated with distilled water (CNE) compared to the normal control $(\mathrm{CN})$. Contrarily, in the animals treated with the extract at a dose of 75, 150, $300 \mathrm{mg} / \mathrm{kg}$ (CT 75, CT 150, CT 300 ) and the positive control (PC), no significant change was observed in the bodily weight. compared to normal

\section{Effect of aqueous extract of Commiphora pedunculata on food consumption}

Figure 3 shows the effect of the aqueous extract of $C$. pedunculata on the food consumption of rats made diabetic by streptozotocin. It can be seen that there was no significant difference in the said consumption in all animals on days 1,3 and 7 of the experiment, compared to the normal control $(\mathrm{CN})$. On the other hand, on days 14 and 21, there was a slight increase and then a highly significant increase $(* * p<0.001)$ in food consumption in the negative control group (CNE) compared to the normal control $(\mathrm{CN})$. As for the other groups treated with the aqueous extract of the plant, no significant difference was noted compared to the normal control.

\section{Effect of aqueous extract of $C$. pedunculata on water consumption of animals}

Figure 4 shows the effect of aqueous extract of $C$. pedunculata on the water consumption of rats within $24 \mathrm{~h}$. It emerges from this figure that the water consumption increases in all the different groups of rats on the 3rd day.

In the negative control group (CNE), this increase is gradual and continues significantly ( $\mathrm{P}<0.05)$ until day 21 compared to the normal control $(\mathrm{CN})$. In contrast, in the groups treated with the aqueous extract, there is a slight decrease in water consumption from the 14th and 21 st. 
Effect of aqueous extract of $C$. pedunculata on blood glucose levels of rats during experimentation

Figure 5 shows the effect of the aqueous extract of $C$. pedunculata on the blood sugar level of rats during 21 days. From this figure, it can be seen that, the blood glucose levels of the animals is the same on the 1st day of the experiment.

Moreover, we notice that, the blood glucose of the streptozotocin injected rats (rats treated with distilled water, glibenclamide and different doses of extract) increased in a highly significant manner $(\mathrm{p}<0.001)$ on day 3 , 14 and 21 compared to that of the normal control group. However, treatment with glibenclamide and extract at doses of 75 $\mathrm{mg} / \mathrm{kg}, 150 \mathrm{mg} / \mathrm{kg}$ and $300 \mathrm{mg} / \mathrm{kg}$ resulted in a decrease in blood glucose level (cp <0.001; bp $<0.01$; ap $<0.05)$ compared to the negative control, from day 7,14 to 21 .

Effect of the aqueous extract of $C$. pedunculata on the lipid profile of rats

Figure 6 below shows the effect of the aqueous extract of $C$. pedunculata on the lipid parameters of rats. Here to see that the levels of total cholesterol, triglycerides and LDL-C significantly increased in the negative control rats compared to the normal control. On the other hand, in the positive control group (PC) and the different test controls (TC 75, TC 150 and TC $300 \mathrm{mg} / \mathrm{kg}$ ), no significant difference was noted compared to the normal control.

However, the high-density lipoprotein (HDLc) level of the negative control group experienced a significant decreased $(\mathrm{p}<0.05)$ compared with the HDL-c level of the normal control group. Therefore, treatment with the extract at doses of 75,150 and $300 \mathrm{mg} / \mathrm{kg}$ resulted in a significant increase in HDL-c levels compared to the negative control group.
Effect of aqueous extract of $C$. pedunculata on the histology of the pancreas

Figure 7 shows us the effects of the different treatments on the microarchitecture of the pancreas. According to this figure, a decrease in the size of the pancreatic islets is observed in the negative control group compared to the normal control group. Administration of plant extract at doses of 75,150 and $300 \mathrm{mg} / \mathrm{kg}$ compared to the negative control group increased the size of pancreatic islets control receiving distilled water $(10 \mathrm{~mL} / \mathrm{kg}), \mathrm{PC}=$ Positive control receiving glibenclamide at the dose of $4 \mathrm{mg} / \mathrm{kg}$, CT1, CT2, and CT3, = Animals treated with aqueous extract of $C$. pedunculata at the dose of 75,150 , and 300 $\mathrm{mg} / \mathrm{kg}$. Pen = Endocrine pancreas, Pex = Exocrine pancreas.

Phytochemical evaluation of the aqueous extract of $C$. pedunculata showed the presence of some compounds such as saponins, phenols, tannins, anthraquinones, flavonoids and terpenoids; which is believed to have antidiabetic properties (5).

The results obtained in our study showed that, STZ which was used to induce diabetes caused a loss of body weight in rats. The decrease in body weight observed in the negative control group would be due, on the one hand, to the hydrolysis of protein and lipid reserves at the level of the tissues for energy production, because of the inability of the cells to use blood glucose (5). On the other hand, this weight loss of animals would probably be due to insulin deficiency which leads to a decrease in amino acid uptake by tissues with a consequent reduction in protein synthesis (6).

In treated diabetic groups, administration of the aqueous extract of $C$. pedunculata by gavage at daily doses of 150 and $300 \mathrm{mg} / \mathrm{kg}$ improved the change in body weight. The 
action of the aqueous extract of this plant in protecting diabetic rats from excessive loss of body weight would be due to neither its ability to inhibit lipolysis nor its hypoglycemic effect (7).

Polyphagia observed during diabetes process is a condition in which there is an exaggerated consumption of food. STZ injection induced diabetes accompanied by a significant $(\mathrm{p}<0.05)$ increase in food consumption on days 15 and 21 in negative control rats compared to normal control. This is the result of an almost total deficit in insulin, whose role is to capture and usage of glucose by the cells of the body, which causes a lack of energy, (lack of use of glucose and its escape at the level of the renal tubules). In rats treated with glibenclamide and aqueous extract of $C$. pedunculata, there was a slight decrease in the daily consumption of food compared to that of normal control rats. Our results are similar to those obtained by (8) who showed that there is a decrease in food consumption in diabetics treated with hydroethanolic and methanolic extracts of Artemisia amygdalina compared to the diabetic control.

The volume of water consumed during the period of experimentation, is measured daily since polydipsia is a symptom of diabetes. This polydipsia induced in the rats after the injection of STZ, causes an increase in daily water consumption in the diabetic control group compared to the normal control group. In the diabetic group of rats, treatment with the aqueous extract of the plant at different doses and that of glibenclamide caused a reduction in this daily water consumption compared to that recorded in the healthy control rats. This could be explained by the fact that, polydipsia is caused by dehydration which stimulates the hypothalamic thirst centers (9). In addition, this could be due to the fact that the concentration of glucose being high in the blood, the body seeks to bring this concentration back to normal by absorbing a lot of water.

Chronic induced hyperglycemia can be explained by many mechanisms, ranging from increased hepatic neoglucogenesis to the synergistic effects of corticosteroids, to proteolysis and lipolysis. In the present work, the pathology results from an irreversible destruction of pancreatic $\beta$-cells, causing a reduction in insulin secretion. The latter is clearly depleted, but not absent (10). Infact, glucose, which constitutes the STZ molecule, allows its penetration into the pancreatic $\beta$ cells through the glucose transporters GLUT2 (11). Inside the cell, STZ causes the release of nitrogen monoxide (NO), production of reactive oxygen species (ROS), alkylation of DNA, depletion ATP of $\beta$-cell, and inhibition of the enzyme $\mathrm{N}$-acetyl glucosamine selective $\mathrm{N}$-glycosylation of acetyl-BDglucosaminidase proteins and irreversible (12). The results obtained in our study (Figure 17) on blood glucose showed that STZ caused after 3 days an increase in the blood glucose of the rats (negative control and test controls) compared to the group of normal control rats. This hyperglycemia is explained by the direct toxicity of STZ on $\beta$-cells, resulting in necrosis after 48 to 72 hours and causes permanent hyperglycemia (11).

Diabetes mellitus is associated with dyslipidemia, which is reflected by a decrease in HDL cholesterol and an increase in total cholesterol, triglycerides, LDL cholesterol and VLDL cholesterol (13). In the present study, compared to the diabetic control batch treated with distilled water, glibenclamide and/or the different doses of extract induced a significant increase in HDL cholesterol levels and a significant decrease in triglyceride and LDL cholesterol levels. Our results are in agreement with those obtained by (14) who observed an increased concentration in serum lipids in diabetic subjects. 
Table.1 Different families of chemical compounds present in the aqueous extract of $C$. pedunculata

\begin{tabular}{|c|c|}
\hline Families of chemical compounds & Presence \\
\hline Phenol compounds & + \\
\hline Flavonoids & + \\
\hline Tannins & + \\
\hline Saponins & + \\
\hline Alkaloids & + \\
\hline Glucosides & - \\
\hline Anthraquinones & + \\
\hline Coumarin & - \\
\hline Terpenoids & + \\
\hline Lipids & - \\
\hline Present (+) Absent (-) \\
\hline
\end{tabular}

Fig.1 Effect of aqueous extract of $C$. pedunculata trunk bark on D-glucose tolerance test. Each point represents the mean $\pm \operatorname{ESM}(\mathrm{n}=5)$. (* $\mathrm{p}<0.05$; ** $\mathrm{p}<0.01$; *** $\mathrm{p}<0.001)$ significant variation compared to time; $30 \mathrm{~min}$.

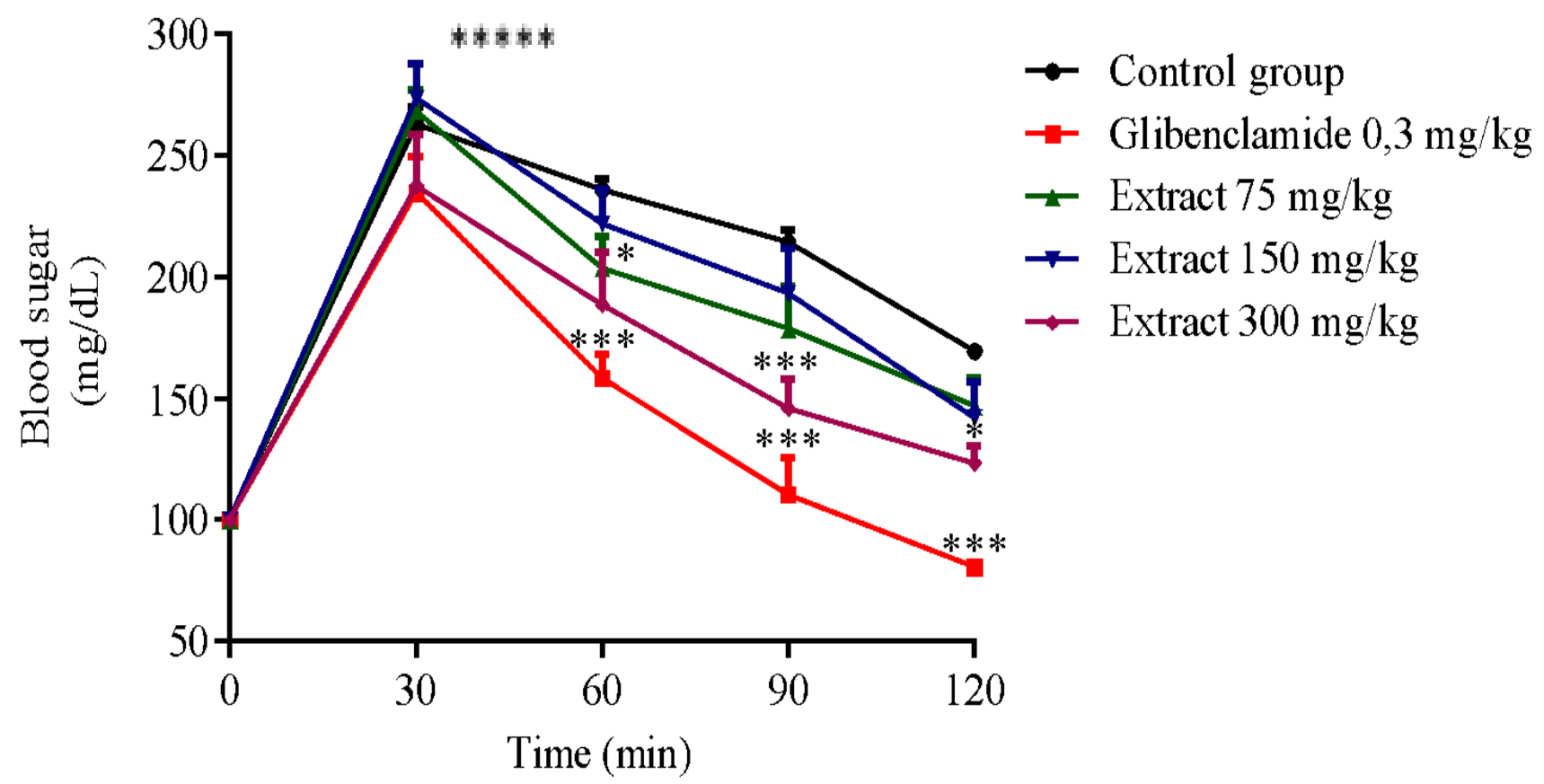


Fig.2 Effect of aqueous extract of $C$. pedunculata on body weight of rats. Each bar represents the mean \pm MSE, $(n=5) .(* * \mathrm{p}<0.01)$ highly significant variation relative to the normal control. $\mathrm{NC}=$ Normal control, $\mathrm{PC}=$ Positive control, $\mathrm{NCB}=$ Negative control, CT75, CT150, CT300= Doses 75,150 and $300 \mathrm{mg} / \mathrm{kg}$.

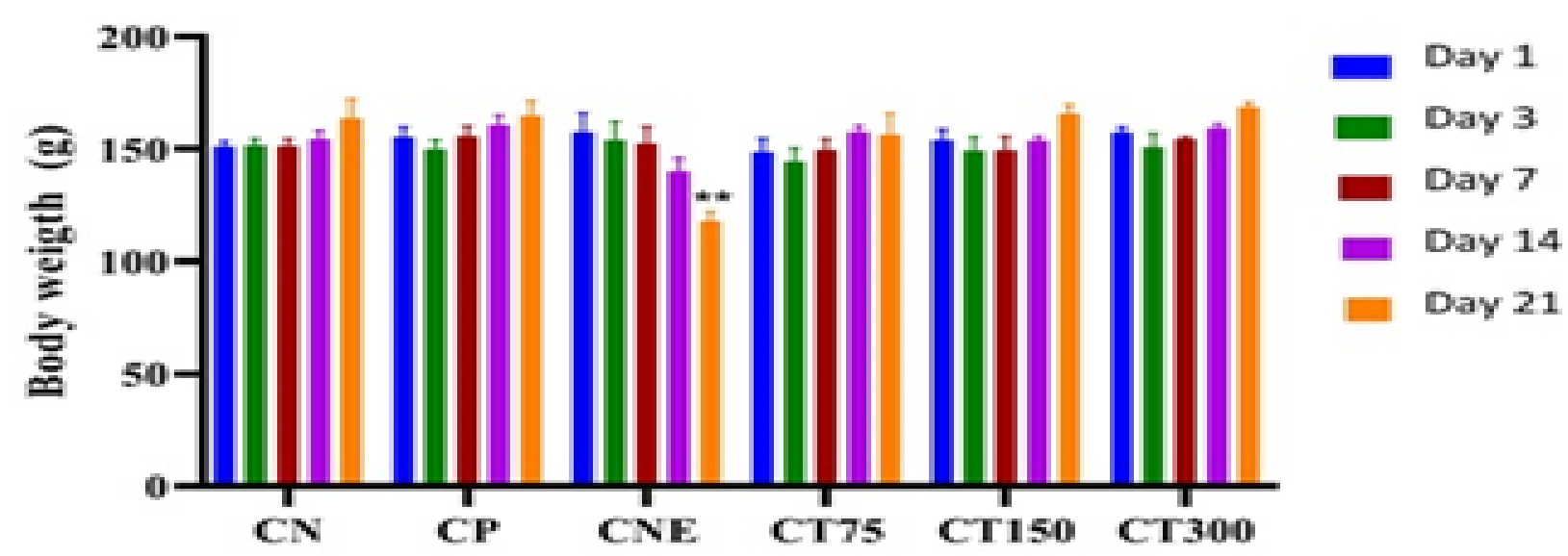

Fig.3 Effect of the aqueous extract of the bark of $C$. pedunculata on the food consumption of rats. Each histogram represents the mean \pm ESM, $(n=5)$. (** $\mathrm{p}<0.001)$ Highly significant change relative to the normal control. $\mathrm{CN}=$ Normal Control; $\mathrm{CP}=$ Positive Control; $\mathrm{CNE}=$ Negative Control; CT75, CT150 and CT300 = Doses 75, 150 and 300mg / kg.

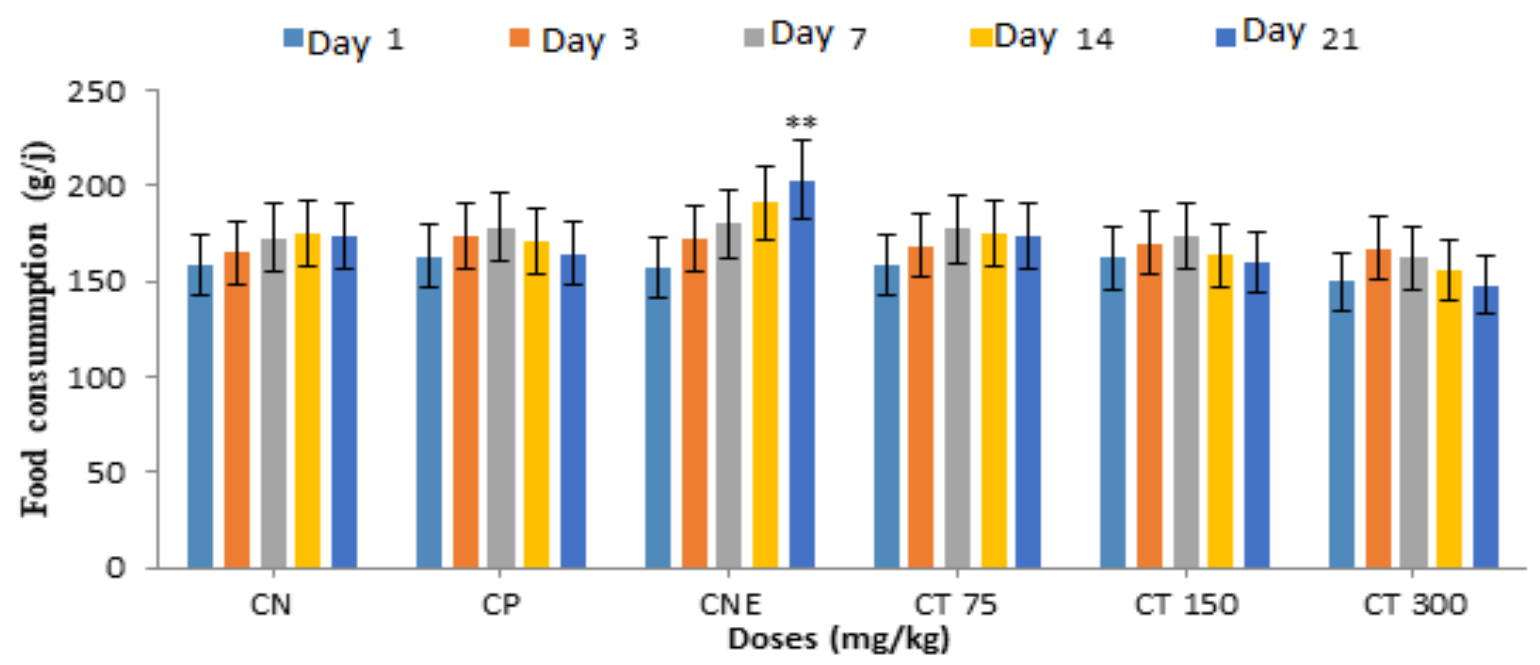


Fig.4 Effect of $C$. pedunculata aqueous extract on daily water consumption in rats. Each histogram represents the mean \pm MSE, $(n=5) .(* p<0.05)$ Significant change compared to the normal control. $\mathrm{NC}=$ Normal control; $\mathrm{PC}=$ Positive control; NEC $=$ Negative control; CT75, CT150 and CT300= Doses 75, 150 and 300mg/kg.

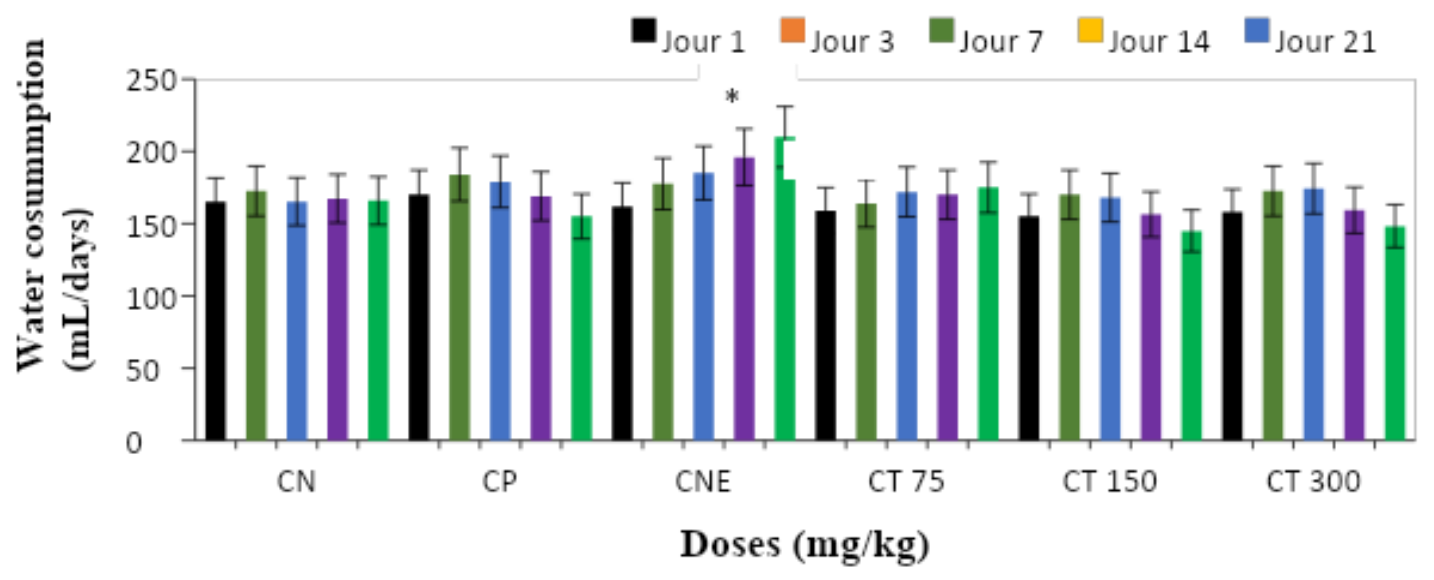

Fig.5 Effects of aqueous extract of $C$. pedunculata on blood glucose variation in insulindependent animals. Each bar represents the mean \pm MSE. $n=5(* * * p<0.001)$ highly significant variation from normal control. $\mathrm{NC}=$ Normal control, $\mathrm{PC}=$ Positive control, $\mathrm{NCB}=$ Negative control, $($ CT75, CT150, CT300) $=$ Different doses of extract.

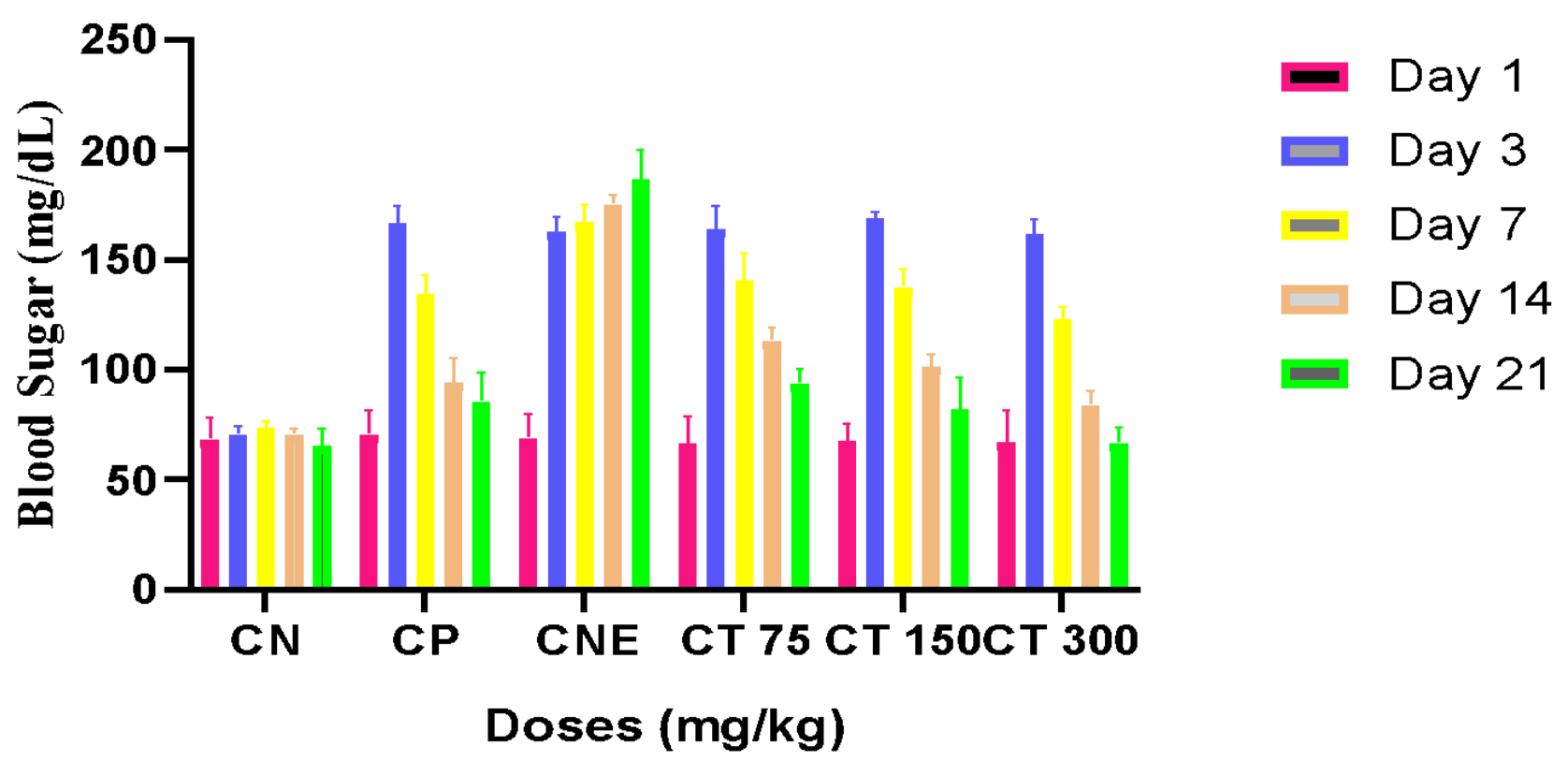


Fig.6 Effect of aqueous extract of C. pedunculata on the lipid profile of rats. Data were expressed as mean \pm MSE. $(\mathrm{n}=5)$, Statistical difference is considered significant $\left({ }^{*} \mathrm{p}<0.05\right)$ compared with normal control. $\mathrm{NC}=$ Normal control, $\mathrm{PC}=$ Positive control, $\mathrm{NCB}=$ Negative control, $($ CT75, CT150, CT300 $)=$ Different doses of extract.

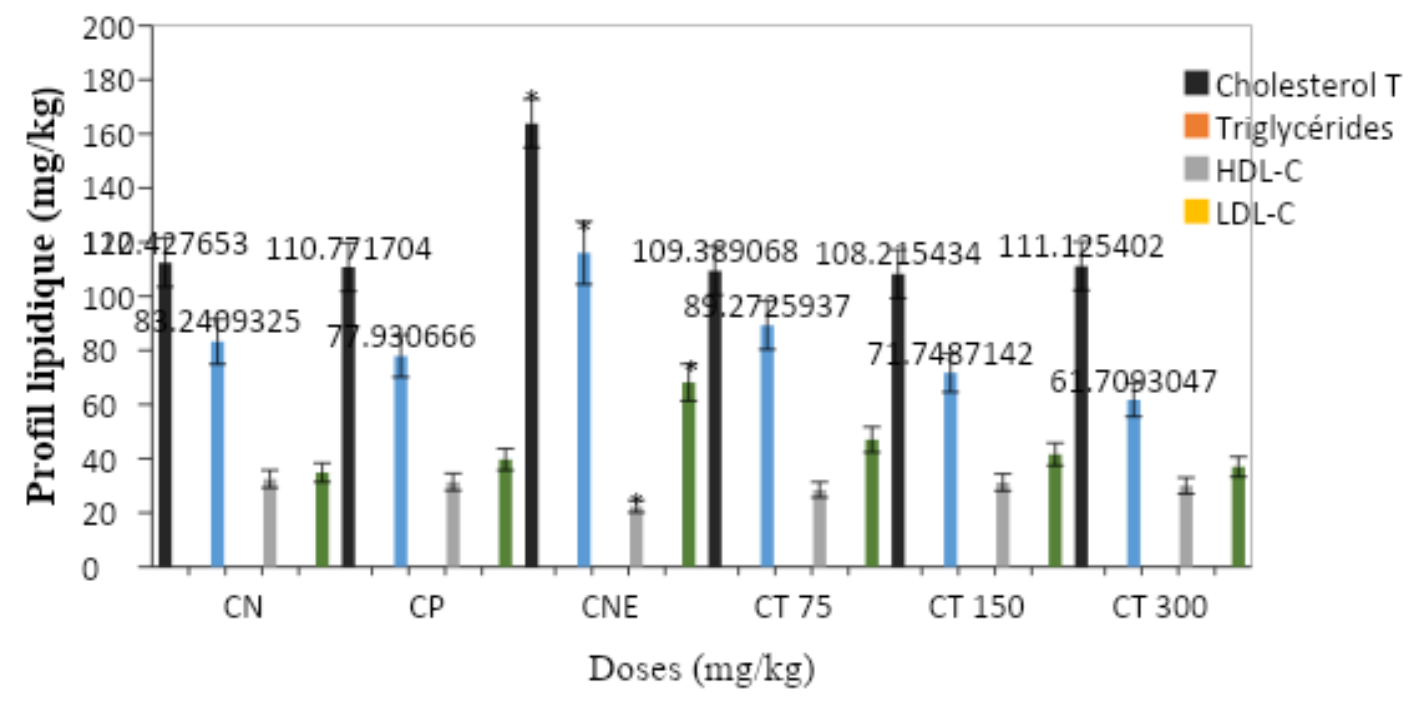

Fig.7 Histological sections of the pancreas (X100) of diabetic rats treated with aqueous extract of C. pedunculata bark. $\mathrm{NC}=$ Normal control receiving distilled water $(10 \mathrm{~mL} / \mathrm{kg}) ; \mathrm{NEC}=$ Negative

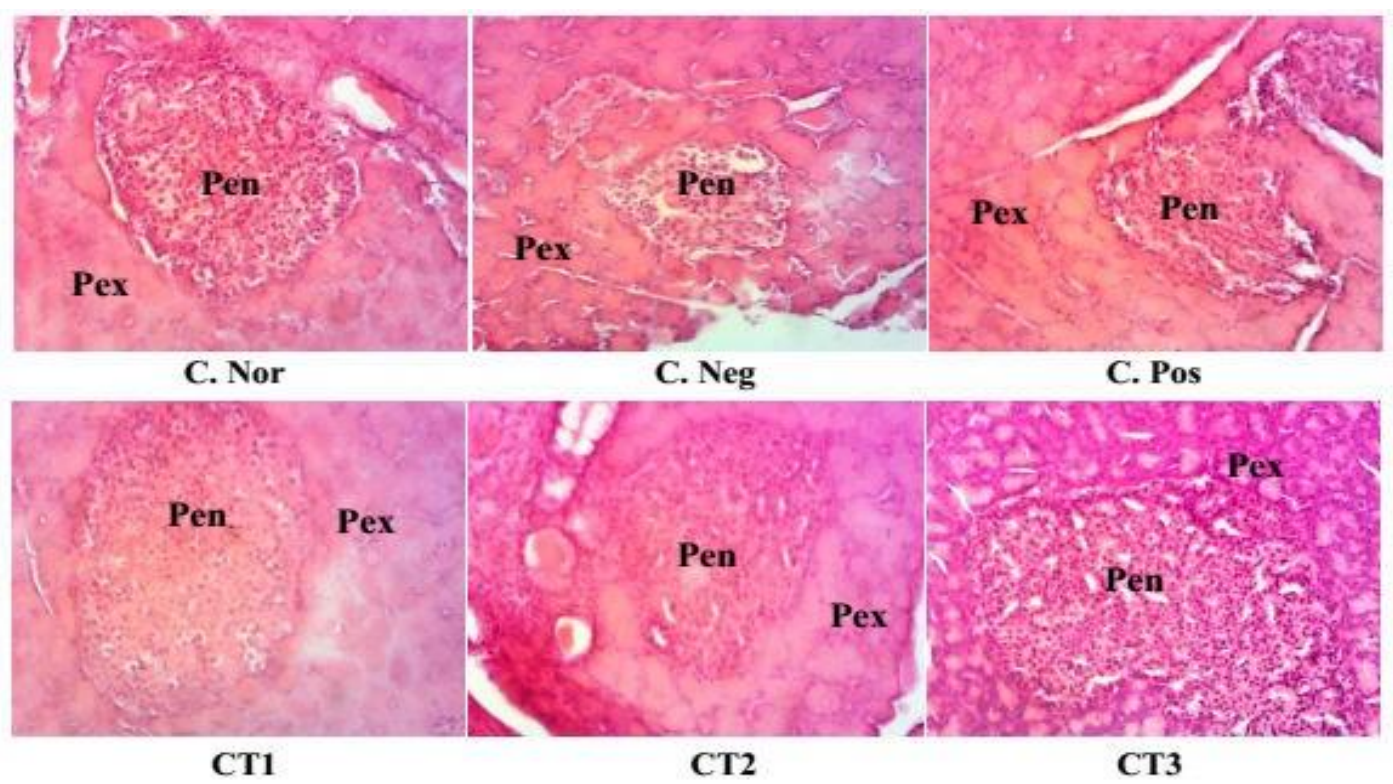

Furthermore, Betterridge et al., (2002) (15) reported that insulin deficiency or insulin resistance may be responsible for hyperlipidemia. However, the extract improved the lipid profile by reducing the levels of total cholesterol, triglycerides, LDL$\mathrm{C}$ while increasing HDL-C in animals. The extract would probably act by decreasing 
cholesterol biosynthesis specifically by reducing the activity of 3-hydroxy-3-methylglutaryl glutaryl A reductase (HMG-CoA reductase, a key enzyme in cholesterol biosynthesis) (16).

Histology of the endocrine pancreas of rats subjected to streptozotocin after 72 hours reveals endocrine islet cell degeneration, mild cytoplasmic necrosis with a regular nucleus. Observations have indicated that STZ injection causes degenerative and necrotic changes, with the shrinkage of islet cells of Langerhans. The pathological changes observed in the present work can be explained by the work of (17), who showed that STZ is taken up by pancreatic $\beta$-cells through the GLUT 2 transporter where it causes $\beta$-cell death by DNA fragmentation by the nitrosourea moiety. Histological sections of the pancreas of diabetic rats treated with $C$. pedunculata show the presence of highly delimited islets of Langerhans with very little cellular necrosis. This could mean that the plant has a protective effect on the structure and function of Langerhans $\beta$-cells. This protective effect of the islets observed could be due to the presence of anti-diabetic compounds revealed by the phytochemical study. Indeed, it has been reported that flavonoids have the ability to regenerate Langerhans beta cells and thus restore insulin secretion in rats made diabetic by alloxane (18). Our plant contains these families of molecules (flavonoids, triterpenes and tannins), and it is impossible that one or the other or the synergy of these compounds is responsible for the cellular protection of islets of Langerhans'.

The aqueous extract of Commiphora pedunculata does have anti-diabetic properties, it caused a decrease in blood glucose level, lipids and have protected some organs in rats due to its phytochemical components. The next study will be to isolate the most active molecule of the plant and to study its mechanism of action.

\section{Acknowledgement}

The authors thank the Laboratory of the Medicinal Plants, Health and Galenic Formulation of the Department of Biological Sciences, University of Ngaoundéré.

\section{References}

Dubois-Laforgue (2007). Étiologie et physiopathologie du diabète de type 1 . EndocrinologieNutrition. 1-18.

Guenzet A (2012). Effets des extraits aqueux lyophilisés de Portulcaoleracea et Zygophyllum gaetulum sur le profil lipidique et le statut redox, chez les rats rendus diabétiques par injection de streptozotocine. Diplôme de Magister, Université d'Oran.

Al-Achi A (2005). Herbs that affect blood glucose levels.Women's Health in Primary Care.Vol 8, No 7: 325-330.

Fédération Internationale du Diabète 2017 for 2019 and projections for 2030 and 2045: results from the

Middleton.J R. E, Chithan. K. The impact of plant flavonoids on mammalian biology implications for immunity, inflammation and cancer. In: Harborne J.B., editor. The Flavonoids: advances in research since 1986. London, UK.

Farida A., Shoukry M. (1988). The lipid lowering effect of an anti-diabetic plant extract. Acta diabetologica 25(1) $: 1-5$.

Guenzet A (2012). Effets des extraits aqueux lyophilisés de Portulcaoleracea et Zygophyllum gaetulumsur sur le profil lipidique et le statut redox, chez les rats rendus diabétiques par injection de streptozotocine. diplôme de Magister, Université d'Oran

Chen V., Ianuzza C D. Dosage effect of 
streptozotocin on rat tissue enzyme activities and glycogen concentration. Can J Physiol Pharmacol. 1981; 60: 1251-1256

Khalid Ghazanfar, Bashir A. Ganai, Seema Akbar, Khan Mubashir, Showkat Ahmad Dar, Mohammad Younis Dar, andMudasir A. Tantry. Antidiabetic Activity of Artemisia amygdalina Decne in Streptozotocin Induced Diabetic Rats. BioMed Research International

Bouhouche I (2014). Etude comparative de l'alloxane et de la streptozotocine dans le diabète expérimental chez le rat blanc. Etude histologique du pancréas endocrine et la variation des paramètres sanguins. Thèse Magister, Université Constantine 1.

Pushparaj N P, Tan H K B, Tan H C. The mechanism of hypoglycemic action of the semi-purified fractions of Averrhoa bilimbi in streptozotocin diabetic rats. Life Sciences 2001; 70:

Szkudelskit (2001).The Mechanism of Alloxan and Streptozotocin Action in B Cells of the Rat Pancreas. Department of Animal Physiology and Biochemistry, University of Agriculture, Poznan. Poland Received. Vol 50, No 6: 537-546.

Alejandro D. Bolzán., Martha S., Bianchi. Genotoxicity of Streptozotocin. Mutation Research. 2002; 512 : 121-
134.

Ravi K, Ramachandran B, Subramanian S (2005). Effect of Eugenia Jambolana seed kernel on antioxidant defense system in streptozotocin-induced diabetes in rats. Life Sciences. Vol 75, No 22: 2717 - 2731.

Jamkhande P G, Patil P H, Surana S J. Evaluation of n-butanolic fractions of Butea Monosperma flowers on dexamethasone induced hyperglycemia and hyperlipidemia in mice. Int $\mathbf{J}$ Phytopharm Res 2010; 1:1-10.

Betterridge J. Lipid disorders in diabetes mellitus. In: Pickup J, Williams G (eds) Textbook of Diabetes, Blackwell Science, London, UK, pp 551-3, 2002.

Kedar, P., Chakrabarti, C. H., 1982. Effects of bittergourd (Momordica charantia) seed and glibenclamide in streptozotocin induced diabetes mellitus. Indian Journal of Experimental Biology 20, pp. 232235.

Jamkhande P G, Patil P H, Surana S J. Evaluation of n-butanolic fractions of Butea Monosperma flowers on dexamethasone induced hyperglycemia and hyperlipidemia in mice. Int $\mathbf{J}$ Phytopharm Res 2010; 1:1-10.

Perez, G. A. M., Zavala, S. M. A., Perez., G. S., Perez, G. C.(1998). Antidiabetic effect of compounds isolated from plants. phytomedicine.5:55-75.

\section{How to cite this article:}

Lawa Wanlibélé, Ntchapda Fidèle, Kemeta Azambou David Romain, Talla Ernest Rodrigue, Miaffo David, Sanone Guersom and Sokeng Dongmo Selestin. 2021. Effect of the Aqueous Extract of the Trunk Bark of Commiphora pedunculata (Burseraceae) on Type 1 Diabetes induced by the Streptozotocin in Rats. Int.J.Curr.Microbiol.App.Sci. 10(08): 76-87. doi: https://doi.org/10.20546/ijcmas.2021.1008.010 